\title{
Phosphate and iron stress control global surface ocean dissolved organic phosphorus concentrations
}

\section{Zhou Liang ( $\nabla$ zl18c@my.fsu.edu )}

Florida State University

Robert Letscher

University of New Hampshire https://orcid.org/0000-0002-3768-9003

Angela Knapp

Florida State University https://orcid.org/0000-0001-5575-3382

\section{Article}

Keywords: dissolved organic phosphorus, phosphate stress, chlorophyll a

Posted Date: August 10th, 2021

DOl: https://doi.org/10.21203/rs.3.rs-726745/v1

License: (1) (1) This work is licensed under a Creative Commons Attribution 4.0 International License.

Read Full License

Version of Record: A version of this preprint was published at Nature Geoscience on July $21 \mathrm{st}, 2022$. See the published version at https://doi.org/10.1038/s41561-022-00988-1. 


\section{Phosphate and iron stress control global surface ocean dissolved organic phosphorus concentrations}

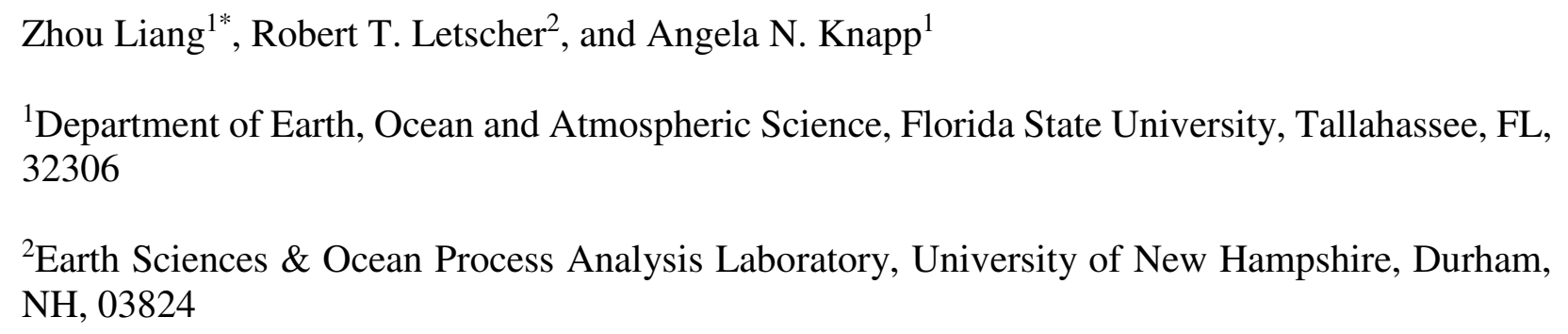

${ }^{1}$ Department of Earth, Ocean and Atmospheric Science, Florida State University, Tallahassee, FL, 32306

${ }^{2}$ Earth Sciences \& Ocean Process Analysis Laboratory, University of New Hampshire, Durham, $\mathrm{NH}, 03824$

Corresponding author: Zhou Liang (zl18c@my.fsu.edu)

\section{Abstract}

Dissolved organic phosphorus (DOP) has a dual role in the surface ocean as both a product of

20 primary production and as an organic nutrient fueling primary production and nitrogen fixation,

21 especially in oligotrophic gyres. Though poorly constrained, understanding the geographic

22 distribution and environmental controls of surface ocean DOP concentration is critical to

23 estimating distributions and rates of primary production and nitrogen fixation in the global ocean.

24 Here we pair DOP concentration measurements with a metric of phosphate $\left(\mathrm{PO}_{4}{ }^{3-}\right)$ stress $\left(\mathrm{P}^{*}\right)$, and

25 satellite-based chlorophyll $a$ concentrations and iron stress estimates to explore their relationship

26 with upper $50 \mathrm{~m}$ DOP stocks. Our results show that $\mathrm{PO}_{4}{ }^{3-}$ and iron stress work together to control

27 surface DOP concentrations at basin scales. Specifically, upper $50 \mathrm{~m}$ DOP stocks decrease with

28 increasing phosphate stress, while alleviated iron stress leads to either surface DOP accumulation

29 or loss depending on $\mathrm{PO}_{4}{ }^{3-}$ availability. Our work suggests an interdependence between DOP

30 concentration, inorganic nutrient ratios, and iron availability, and establishes a predictive

31 framework for DOP distributions in the global surface ocean. 


\section{Main}

34 In oligotrophic gyres, dissolved organic phosphorus (DOP) is the dominant form of phosphorus

35 (P) in surface waters $^{1-3}$ and supports phytoplankton growth when the preferred substrate, 36 phosphate $\left(\mathrm{PO}_{4}{ }^{3-}\right)$, is scarce ${ }^{4-10}$. Estimates from the Biogeochemical Elemental Cycling (BEC)

37 model indicate that global marine net primary production (NPP) and di-nitrogen $\left(\mathrm{N}_{2}\right)$ fixation rates 38 are $\sim 8 \%$ and $\sim 33 \%$ higher, respectively, and better match observed rates, when they include DOP

39 as an assimilative $\mathrm{P}$ source ${ }^{11}$. Like dissolved organic carbon and nitrogen (DOC and DON) in the

40 ocean, DOP is a product of primary production ${ }^{12}$. However, a clear understanding of both the

41 distribution of DOP in the global surface ocean as well as the controls on those distributions is

42 limited by the relatively small number of DOP concentration measurements in the global ocean ${ }^{11}$.

43 A mechanistic framework to understand the controls on surface ocean DOP concentrations would

44 thus improve model-based estimates of the rates and distributions of marine NPP and $\mathrm{N}_{2}$ fixation.

46 Given that DOP is both produced and consumed by photosynthetic organisms, we explored

47 relationships between DOP distributions and metrics of primary production (i.e., DOP production),

$48 \mathrm{PO}_{4}{ }^{3-}$ stress (i.e., DOP consumption), as well as iron stress, which can limit primary production.

49 Additionally, iron has recently been identified as a co-factor in a version of the enzyme responsible

50 for DOP utilization by phytoplankton, alkaline phosphatase ${ }^{10,13,14}$, and thus iron availability may

51 also affect DOP consumption. To test these relationships, we paired surface ocean DOP

52 concentration measurements (Fig. 1) with satellite-based measurements of chlorophyll $a$ 53 concentration, climatological "excess $\mathrm{PO}_{4}{ }^{3-"}$ or " $\mathrm{P} *$ " values evaluated in surface waters $(<5 \mathrm{~m})$, 54 where $\mathrm{P}^{*}$ is defined as $\left[\mathrm{PO}_{4}^{3-}\right]-\left(\left[\mathrm{NO}_{3}{ }^{-}\right] / 16\right)^{15}$, and satellite-derived iron stress estimates ${ }^{16}$ (Figs.

55 1,2). We find that upper $50 \mathrm{~m}$ DOP concentrations are significantly positively correlated with 
56 surface $\mathrm{P}^{*}$ values $\left(\mathrm{R}^{2}=0.28, \mathrm{p}<0.000001\right)$ (Fig. $\left.1 \mathrm{~b}\right)$. Here, higher $\mathrm{P}^{*}$ values correspond to lower

$57 \mathrm{PO}_{4}{ }^{3-}$ stress, consistent with stoichiometric biomass demands for $\mathrm{N}$ and $\mathrm{P}^{17}$, as well as $\mathrm{PO}_{4}{ }^{3-}$

58 concentration thresholds for DOP utilization by phytoplankton ${ }^{2}$. In addition to $\mathrm{PO}_{4}{ }^{3-}$ stress, iron

59 stress also plays a significant but more complicated role regulating surface DOP concentrations

60 and can lead to either surface DOP accumulation under enhanced iron stress or consumption under

61 alleviated iron stress. Based on these relationships, we present a conceptual model of the factors

62 controlling surface ocean DOP concentrations.

\section{Global regions of net DOP production and loss}

65 The ultimate source of dissolved organic matter (DOM) to the ocean is marine primary production,

66 and DOC and DON accumulate in regions with elevated productivity ${ }^{18-21}$. Similar to DOC and

67 DON, we find that upper $50 \mathrm{~m}$ DOP stocks are significantly positively correlated with satellite-

68 based measures of chlorophyll $a$ concentration on the P18-2016 GO-SHIP and BIOSOPE cruises $^{22}$

69 in the Eastern Pacific as well as in the Gulf of Mexico (Figs. 1, 2, Table 1). Correspondingly, the

70 Eastern North and South Pacific Ocean and Gulf of Mexico have the highest mean surface ocean

71 DOP concentrations in our dataset, averaging $0.34 \pm 0.07 \mu \mathrm{M}, 0.23 \pm 0.07 \mu \mathrm{M}$, and $0.23 \pm 0.07 \mu \mathrm{M}$

72 (Fig. S1), respectively, and represent regions of net DOP production. In contrast, North Atlantic

73 and Western North and South Pacific surface ocean DOP and chlorophyll $a$ concentrations are

74 significantly negatively correlated (Fig. 2, Table 1). In these samples, when chlorophyll $a$ is high,

75 DOP concentrations are low, indicating that these regions are not associated with DOP production,

76 but that instead DOP is used as an assimilative P source sustaining productivity. Thus, the North

77 Atlantic, Western North and South Pacific Oceans appear to be net sinks for DOP, and have the

78 lowest observed basin-mean concentrations, $0.10 \pm 0.07 \mu \mathrm{M}, 0.12 \pm 0.02 \mu \mathrm{M}$ and $0.14 \pm 0.04 \mu \mathrm{M}$ (Fig. 
79 S1), respectively, all of which are statistically significantly lower than the mean values in the

80 Eastern Pacific and Gulf of Mexico (Fig. S1). Below we explore the interdependence of surface

81 ocean DOP concentrations, primary productivity, $\mathrm{PO}_{4}{ }^{3-}$ stress $\left(\mathrm{P}^{*}\right)$, and surface ocean iron

82 availability.

\section{$84 \mathrm{PO}_{4}{ }^{3-}$ as the primary control on surface ocean DOP concentrations}

85 The primary control on surface ocean DOP concentrations is $\mathrm{PO}_{4}{ }^{3-}$ stress, gauged by $\mathrm{P}^{*}$, with upper

$8650 \mathrm{~m}$ DOP stocks in all data sets significantly positively correlated with $\mathrm{P}^{*}$ (Fig. 1b) (Table. 1).

87 Global regions of net DOP production in the Eastern Pacific are associated with elevated $\mathrm{P}^{*}$ values,

88 typically $>0.2 \mu \mathrm{M}$ (Fig. 1b), generated by subsurface denitrification and anammox in the oxygen

89 deficient zones (ODZs) in and upstream of these sampling locations ${ }^{23}$. Surface waters with high

$90 \mathrm{P}^{*}$ values thus correspond to regions with "excess $\mathrm{PO}_{4}^{3-6,}$, or low $\mathrm{PO}_{4}{ }^{3-}$ stress, relative to supplies

91 of $\mathrm{NO}_{3}{ }^{-}$and "Redfieldian" phytoplankton $\mathrm{N}$ and $\mathrm{P}$ demands ${ }^{15,17}$. The upwelling-driven elevated

92 DOP production in regions with low $\mathrm{PO}_{4}{ }^{3-}$ stress allows DOP to accumulate to relatively high

93 concentrations in the Eastern Pacific, as observed in the P18-2016 GO-SHIP and BIOSOPE ${ }^{22}$ data

94 sets, as well as in the Gulf of Mexico (Figs. 1, 2). While high $\mathrm{P}^{*}$ values, and thus low $\mathrm{PO}_{4}{ }^{3-}$ stress,

95 are correlated with elevated DOP concentrations in surface waters above the Eastern Pacific ODZs,

96 DOP consumption happens elsewhere in the global ocean with low $\mathrm{P}^{*}$ values, and thus higher

$97 \mathrm{PO}_{4}{ }^{3-}$ stress. In particular, samples from the North Atlantic and Western North and South Pacific

98 Oceans show decreasing upper 50 m DOP stocks with increasing chlorophyll a concentration (Figs.

99 1, 2), consistent with previous observations of DOP being an important assimilative P source

100 sustaining autotrophs in the Sargasso $\mathrm{Sea}^{2,3,5,7,24}$. Given the significant correlation of upper $50 \mathrm{~m}$

101 DOP stocks and $\mathrm{P}^{*}$ (Fig. 1), $\mathrm{PO}_{4}{ }^{3-}$ stress is considered the primary control on surface ocean DOP 
distributions.

103

\section{Iron stress modifies surface ocean DOP accumulation and loss}

105 Whereas higher $\mathrm{PO}_{4}{ }^{3-}$ stress leads to enhanced DOP consumption on the global scale, alleviated 106 iron stress can promote either DOP production or consumption. Here, remote sensing products are

107 used to evaluate iron stress experienced by phytoplankton ${ }^{16}$. In the P18-2016 GO-SHIP and 108 BIOSOPE $^{22}$ Eastern Pacific samples, iron stress and upper $50 \mathrm{~m}$ DOP stocks are significantly 109 negatively correlated (Table 1), which we interpret to reflect enhanced DOP production when iron 110 stress is alleviated in high-chlorophyll $a$ upwelling regions (Fig. 2). A significant negative 111 correlation between upper $50 \mathrm{~m}$ DOP stocks and iron stress is also found on the West Florida Shelf 112 in the Gulf of Mexico (Table 1) (Fig. 2). On the global scale, the Eastern Pacific appears unique 113 as a region of net DOP production in upwelling-associated, relatively low-iron stress surface

114 waters, with that DOP subsequently advected west away from regions of net DOP production and 115 accumulating due to low $\mathrm{PO}_{4}{ }^{3-}$ stress in the eastern portion of the Pacific.

117 In contrast to the Eastern Pacific and Gulf of Mexico, basins with net DOP consumption exhibit 118 significant positive correlations between upper $50 \mathrm{~m}$ DOP stocks and iron stress (Table 1) (Fig. 2). 119 Specifically, in samples from the P06-2017 GO-SHIP cruise in the subtropical South Pacific, and 120 the AMT17, AMT14 and 36N cruises $^{2}$ from the Atlantic Ocean, and the KH12-3 cruise ${ }^{25}$ from the

121 Western North Pacific Ocean, upper 50 m DOP stocks increase with increasing iron stress (Fig.

122 2). We interpret the higher DOP stocks in these waters with higher iron stress to reflect iron

123 limitation of primary productivity, and thus decreasing demand for DOP as an assimilative $\mathrm{P}$ 124 source, and/or iron limitation of alkaline phosphatase activity ${ }^{14,13}$, thus limiting the ability of 
125 phytoplankton to use DOP. The low DOP concentrations $(<0.15 \mu \mathrm{M})$ in the North Atlantic and

126 Western Pacific are found in regions with relatively high chlorophyll $a$ concentrations (i.e.,

127 typically $\left.>0.1 \mathrm{mg} \mathrm{chl} a \mathrm{~m}^{-3}\right)$, low $\mathrm{P}^{*}$ values $(<0.1 \mu \mathrm{M})$, and low iron stress (Fig. 2), consistent with

128 DOP use by phytoplankton associated with oligotrophic environments as an assimilative P source

129 when iron is available and $\mathrm{PO}_{4}{ }^{3-}$ is scarce. The North Atlantic Ocean in particular receives high

130 rates of dust deposition ${ }^{26}$, and the South Western Pacific Ocean may receive significant

131 hydrothermal iron fluxes ${ }^{27}$, lowering iron stress in these regions. These regions are also associated

132 with high rates of $\mathrm{N}_{2}$ fixation ${ }^{28-31}$, which may be due to certain diazotrophs (e.g., Trichodesmium 133 spp.) being particularly well-adapted to utilizing DOP when $\mathrm{PO}_{4}{ }^{3-}$ is scare ${ }^{5,24,32,33}$.

135 Finally, we note that DOP appears to accumulate in other specific regions of the ocean due to 136 convergence of surface currents where iron stress is also high and thus limits productivity. 137 Specifically, in the convergence zone of the South Pacific (Fig. 2d and S2), we observed elevated 138 DOP concentrations $(\sim 0.3 \mu \mathrm{M})$ in waters with high iron stress, low $\mathrm{P}^{*}$, and low chlorophyll $a$ 139 concentrations (Fig 2). The same scenario was also found in the surface convergence zone of the 140 South Atlantic, where the DOP concentration is higher than that of the gyre boundary (Fig. $2 \mathrm{j}$ and

141 S2). We suggest here that DOP will accumulate in the surface convergence zone of the North 142 Pacific, as well, which is another region with high iron stress, low $\mathrm{P}^{*}$, and low chlorophyll $a$ (Fig. 143 S2). Further sampling would test this hypothesis.

\section{Conceptual model of DOP accumulation and loss in the surface ocean}

146 According to the observed relationships between upper $50 \mathrm{~m}$ DOP stocks, surface chlorophyll $a$ 147 concentrations, and $\mathrm{PO}_{4}{ }^{3-}$ and iron stress, we propose a simple conceptual model of the factors 
148 influencing DOP distributions in the surface ocean (Fig. 3). On the global scale, DOP loss is

149 enhanced under elevated $\mathrm{PO}_{4}{ }^{3-}$ stress, which increases to the right along the $\mathrm{x}$-axis in Fig. 3, with

150 surface DOP concentrations decreasing to the right and increasing to the left. Additionally, iron

151 stress promotes both DOP production and consumption, depending on $\mathrm{PO}_{4}{ }^{3-}$ stress. In Figure 3 ,

152 iron stress increases up the y-axis. The four quadrants in Fig. 3 correspond to different $\mathrm{PO}_{4}{ }^{3-}$ and

153 iron stress regimes reflecting the corresponding role of DOP as either a product of or substrate for

154 primary productivity in specific ocean regions.

156 As discussed above, the Eastern Pacific is a highly productive region with low $\mathrm{PO}_{4}{ }^{3-}$ stress,

157 resulting in net DOP production and accumulation (Figs. 1 and 2), and is represented by the two

158 pink quadrants in the left of Fig. 3. Iron stress further influences the magnitude of DOP

159 accumulation under low $\mathrm{PO}_{4}{ }^{3-}$ stress. When both iron and $\mathrm{PO}_{4}{ }^{3-}$ stress are alleviated, such as in

160 surface waters overlying ODZs, enhanced primary production will lead to significant net DOP

161 accumulation, so that DOP has a "production" signature. In contrast, the upper left light pink

162 quadrant reflects regions in the Eastern Pacific Ocean exhibiting more muted net DOP

163 accumulation due to surface ocean convergence of DOP produced in "upstream" regions and to

164 the lower, iron-limited rates of primary productivity locally. Global surface ocean regions with the

165 lowest DOP concentrations are associated with high $\mathrm{PO}_{4}{ }^{3-}$ and low iron stress, such as the North

166 Atlantic and Western North and South Pacific Oceans (Fig. 1). These regions are represented by

167 the dark blue, lower right quadrant in Figure 3, and correspond to regions of net DOP loss that we

168 interpret to reflect use of DOP as an assimilative $\mathrm{P}$ source sustaining productivity, perhaps

169 especially by diazotrophs. Finally, the upper right, light blue quadrant corresponds to regions

170 experiencing elevated $\mathrm{PO}_{4}{ }^{3-}$ and iron stress, potentially including the South Atlantic. The South 
171 Atlantic Ocean receives relatively low atmospheric dust inputs ${ }^{26}$, and the lack of significant rates

172 of water column denitrification and/or anammox in the eastern portion of the basin leaves low $\mathrm{P}^{*}$

173 values in the surface waters (Figs. 1,2). Here, net changes in DOP distributions are small, with the

174 potential co-limitation of primary productivity by $\mathrm{PO}_{4}{ }^{3-}$ and iron.

175

176 Interestingly, the linear regression model used to fit the upper $50 \mathrm{~m}$ DOP stocks vs. P* values (Fig.

177 1) predicts a surface DOP concentration at the BATS site $(46 \pm 22 \mathrm{nM}, 95 \%$ confidence level of

178 best fit line) that is similar to observations $\left(\sim 60 \mathrm{nM}^{3}\right)$. However, the predicted surface DOP

179 concentration at Station ALOHA $(146 \pm 31 \mathrm{nM}, 95 \%$ confidence level of best fit line) is lower than

180 observations $\left(\sim 200 \mathrm{nM}^{34}\right)$. We suggest the difference between the observed surface ocean DOP

181 concentrations and those predicted by the linear regression at Station ALOHA potentially reflects

182 iron limitation of DOP consumption, which is not accounted for in the simple correlation of surface

183 ocean DOP concentration vs. P* values. Given the higher atmospheric dust fluxes to the North

184 Atlantic relative to the North Pacific near Hawaii, it is reasonable to expect that iron limitation

185 plays a smaller role controlling DOP distributions at the BATS site. While the simple linear

186 relationship between $\mathrm{P}^{*}$ and surface DOP concentration does not capture all the processes

187 influencing surface ocean DOP concentration in the global ocean $\left(\mathrm{R}^{2}=0.28\right)$, the surface DOP

188 concentrations predicted by the linear regression reflects observed basic-scale differences in

189 surface DOP concentrations (Fig. S3). Meanwhile, the predicted global surface DOP distribution

190 is much improved when including iron stress, $\mathrm{P}^{*}$, and chlorophyll $a$ concentration as predictors by

191 using two machine learning algorithms (Fig S4, $\mathrm{R}^{2}=0.44$ for support vector machine model and

$192 \mathrm{R}^{2}=0.42$ for boosted tree model), indicating that the influence of iron on DOP accumulation and 193 loss in the surface ocean cannot be ignored. 


\section{Implications}

196 Our observations demonstrate significant, basin-scale differences in correlations of upper $50 \mathrm{~m}$

197 DOP stocks with surface ocean chlorophyll $a$ concentration, climatological upper 50 m inorganic 198 nutrient concentration ratios, and remote sensing products of iron stress. Based on these 199 observations, we present a predictive conceptual model for the controls on surface ocean DOP 200 concentrations. Net DOP production is observed in regions with elevated $\mathrm{P}^{*}$ values and relatively

201 low iron stress, consistent with elevated rates of productivity and low pressure on the DOP pool 202 as an assimilative $\mathrm{P}$ source. Net DOP consumption is apparent in regions with $\mathrm{P}^{*}$ values $<0.1 \mu \mathrm{M}$ 203 and relatively low iron stress, suggesting phytoplankton growth is limited by $\mathrm{PO}_{4}{ }^{3-}$ availability and 204 not iron in these regions. This is consistent with emerging work evaluating the role of $\mathrm{N}, \mathrm{P}$, and 205 Fe limitation in different ocean basins ${ }^{35}$. This mechanistic model of surface DOP concentration

206 distributions in the ocean provides a testable framework for both observational and modeling work, 207 and can help constrain rates of NPP and $\mathrm{N}_{2}$ fixations in the global ocean. Indeed, the region with 208 the greatest net DOP loss, from the eastern to western end of the P06-2017 GO-SHIP cruise in the

209 South Pacific, (i.e., $0.2 \mu \mathrm{M}$ DOP loss between $130^{\circ} \mathrm{W}$ and $80^{\circ} \mathrm{E}$ longitudes), is consistent with

210 where both recent observations and modeling work predicts high rates of $\mathrm{N}_{2}$ fixation ${ }^{30,31,36,37}$,

211 indicating that DOP is likely an important $\mathrm{P}$ source fueling $\mathrm{N}_{2}$ fixation in this region where $\mathrm{PO}_{4}{ }^{3-}$

212 concentrations are low $(<0.1 \mu \mathrm{M})$. Additionally, surface ocean DOP consumption enhances ocean-

213 to-atmosphere methane fluxes ${ }^{38}$, a potent greenhouse gas, and a predictive understanding of where 214 DOP consumption occurs may improve $\mathrm{CH}_{4}$ flux estimates. Finally, we note that geochemical 215 measurements from cruises crossing significant biogeochemical gradients and/or basin-scale 
216 transects paired with remote sensing products provide a unique opportunity to evaluate

217 mechanistic controls on nutrient distributions and their role in fertilizing the ocean.

\section{Methods}

\section{DOP concentration data}

221 The DOP concentration data and additional cruise and sampling information can be found in the 222 DOPv2021 database (https://www.bco-dmo.org/dataset/855139). Briefly, DOP concentrations 223 from the P06-2017 GO-SHIP, P18-2016 GO-SHIP, and GOM2019 cruises were measured via the 224 ash/hydrolysis method, a method recommended for more accurate DOP concentration analysis ${ }^{39}$. 225 DOP concentrations from the AMT17, AMT14 and 36N cruises were measured by the UV 226 oxidation method ${ }^{2,40}$. DOP concentrations from the BIOSOPE and $\mathrm{KH} 12-3$ cruises were measured 227 by the persulfate oxidation method ${ }^{41,22,25}$.

229 Surface $\mathrm{P}^{*}$ values

$230 \mathrm{NO}_{3}{ }^{-}$concentrations $\left(\left[\mathrm{NO}_{3}^{-}\right]\right)$and $\mathrm{PO}_{4}{ }^{3-}$ concentrations $\left(\left[\mathrm{PO}_{4}{ }^{3-}\right]\right)$ are taken from the World Ocean 231 Atlas 2013 climatological field $\left(1^{\circ} \times 1^{\circ}\right)^{42}$ at $0 \mathrm{~m}$ level. $\mathrm{P}^{*}$ is calculated by the equation below with 232 surface $\left[\mathrm{NO}_{3}{ }^{-}\right]$and $\left[\mathrm{PO}_{4}{ }^{3-}\right]$ :

$$
P^{*}=\left[\mathrm{PO}_{4}^{3-}\right]-\frac{\left[\mathrm{NO}_{3}^{-}\right]}{16}
$$

235 DOP data are then paired to the nearest points of $\mathrm{P}^{*}$.

\section{Satellite data products}

\section{Remotely sensed chlorophyll $a$ concentration}


239 Surface chlorophyll $a$ concentrations were taken from the MODIS-AQUA $9 \mathrm{~km}$ resolution

240 product $^{43}$, evaluated as the mean of the monthly value during the period of each cruise. DOP data

241 are paired to the nearest points for correlation analysis.

\section{Iron stress}

243 Remotely sensed fluorescence quantum yields $\left(\varphi_{\text {sat }}\right)$ have been shown to be a good indicator for

244 iron stress experienced by phytoplankton ${ }^{14,42}$. Following the method given by Behrenfeld et al., 2452009 , we calculated the global iron stress $9 \mathrm{~km}$ field by the equation below:

$$
\varphi_{\text {sat }}=0.00043 \frac{\mathrm{nFLH} * \mathrm{iPAR}}{\mathrm{Chl}_{\text {sat }}^{0.684}}
$$

247 In which, nFLH is the normalized fluorescence line height $\left(\mathrm{mW} \mathrm{cm}{ }^{-2} \mu \mathrm{m}^{-1} \mathrm{sr}^{-1}\right)$, iPAR is the 248 instantaneous photosynthetically available radiation $\left(\mu \mathrm{mol}\right.$ photons $\left.\mathrm{m}^{-2} \mathrm{~s}^{-1}\right)$ and $C h l_{\text {sat }}$ is satellite 249 derived chlorophyll $a$ concentration $\left(\mathrm{mg} \mathrm{m}^{-3}\right)$ with OC algorithm. $\varphi_{\text {sat }}$ is unitless. nFLH, iPAR 250 and $C_{\text {sat }} 9 \mathrm{~km}$ fields are all downloaded from MODIS level 3 products 251 (https://oceancolor.gsfc.nasa.gov/13/). The equation above was used to obtain the climatological $252 \varphi_{\text {sat }}$ fields between 2003 and 2019. Note that the equation is a simplified expression for $\varphi_{\text {sat }}$ but 253 its global distribution is indistinguishable from the $\varphi_{\text {sat }}$ field with full expression ${ }^{14}$.

\section{Statistics}

256 We performed a correlation analysis between upper 50 DOP stocks and $\mathrm{P}^{*}$, chlorophyll $a$ 257 concentration, or iron stress by using a Type II linear regression model. The type II linear 258 regression model was calculated in MATLAB (2019a version) with the file 'gmregress.m'45

\section{Acknowledgement}


The work was supported by NSF OCE-1829797 to ANK and NSF OCE-1829916 to RTL.

\section{Data availability}

DOP data used in this study can be found in the DOPv2021 database ( https://www.bco-

\section{Code availability}

Code used to generate figure 1 and figure 2 and perform the analysis is available upon request from the corresponding author.

\section{Author information}

Affiliations

\section{Department of Earth, Ocean and Atmospheric Science, Florida State University, Tallahassee,} FL, 32306

Zhou Liang (ORCID: 0000-0002-4999-7097)

Angela N. Knapp (ORCID: 0000-0001-5575-3382)

\section{Earth Sciences \& Ocean Process Analysis Laboratory, University of New Hampshire, Durham, NH, 03824}

Robert T. Letscher (ORCID: 0000-0002-3768-9003)

Contributions

Z.L. performed the analysis. Z.L. and A.K. designed the study. Z.L., A.K and R.L. wrote the paper. A.K. and R.L. lead the project.

\section{Ethics declarations}

Competing interests

The authors declare no competing financial interests

\section{References}

1. Björkman, K. M. \& Karl, D. M. Bioavailability of dissolved organic phosphorus in the euphotic

302 zone at Station ALOHA, North Pacific Subtropical Gyre. Limnol. Oceanogr. 48, 1049-1057 (2003). 
2. Mather, R. L. et al. Phosphorus cycling in the North and South Atlantic Ocean subtropical gyres. Nat. Geosci. 1, 439-443 (2008).

3. Lomas, M. W. et al. Sargasso Sea phosphorus biogeochemistry: an important role for dissolved organic phosphorus (DOP). Biogeosciences 7, 695-710 (2010).

4. Dyhrman, S. T. et al. Phosphonate utilization by the globally important marine diazotroph

308 Trichodesmium. Nature 439, 68-71 (2006).

309 5. Orchard, E. D., Ammerman, J. W., Lomas, M. W. \& Dyhrman, S. T. Dissolved inorganic and

310 organic phosphorus uptake in Trichodesmium and the microbial community: The importance

311 of phosphorus ester in the Sargasso Sea. Limnol. Oceanogr. 55, 1390-1399 (2010).

312 6. Sato, M., Sakuraba, R. \& Hashihama, F. Phosphate monoesterase and diesterase activities in 313 the North and South Pacific Ocean. Biogeosciences 10, 7677-7688 (2013).

314 7. Reynolds, S., Mahaffey, C., Roussenov, V. \& Williams, R. G. Evidence for production and 315 lateral transport of dissolved organic phosphorus in the eastern subtropical North Atlantic.

316 Glob. Biogeochem. Cycles 28, 805-824 (2014).

317 8. Li, T. et al. Identification and Expression Analysis of an Atypical Alkaline Phosphatase in 318 Emiliania huxleyi. Front. Microbiol. 9, (2018).

319 9. Diaz, J. M. et al. Dissolved Organic Phosphorus Utilization by Phytoplankton Reveals 320 Preferential Degradation of Polyphosphates Over Phosphomonoesters. Front. Mar. Sci. 5, 321 (2018).

322 10. Duhamel, S. et al. Phosphorus as an integral component of global marine 323 biogeochemistry. Nat. Geosci. 14, 359-368 (2021). 
324 11. Letscher, R. T. \& Moore, J. K. Preferential remineralization of dissolved organic

325 phosphorus and non-Redfield DOM dynamics in the global ocean: Impacts on marine

326 productivity, nitrogen fixation, and carbon export. Glob. Biogeochem. Cycles 29, 325-340

327 (2015).

328 12. Carlson, C. A. \& Hansell, D. A. Chapter 3 - DOM Sources, Sinks, Reactivity, and Budgets.

329 in Biogeochemistry of Marine Dissolved Organic Matter (Second Edition) (eds. Hansell, D. A.

330 \& Carlson, C. A.) 65-126 (Academic Press, 2015). doi:10.1016/B978-0-12-405940-5.00003-0.

331 13. Browning, T. J. et al. Iron limitation of microbial phosphorus acquisition in the tropical

332 North Atlantic. Nat. Commun. 8, 15465 (2017).

333 14. Mahaffey, C., Reynolds, S., Davis, C. E. \& Lohan, M. C. Alkaline phosphatase activity in

334 the subtropical ocean: insights from nutrient, dust and trace metal addition experiments.

335 Front. Mar. Sci. 1, (2014).

336 15. Deutsch, C., Sarmiento, J. L., Sigman, D. M., Gruber, N. \& Dunne, J. P. Spatial coupling of

337 nitrogen inputs and losses in the ocean. Nature 445, 163-167 (2007).

338 16. Behrenfeld, M. J. et al. Satellite-detected fluorescence reveals global physiology of

339 ocean phytoplankton. Biogeosciences 6, 779-794 (2009).

340 17. Quigg, A. et al. The evolutionary inheritance of elemental stoichiometry in marine

341 phytoplankton. Nature 425, 291-294 (2003).

342 18. Bronk, D. A. \& Ward, B. B. Gross and net nitrogen uptake and DON release in the

343 euphotic zone of Monterey Bay, California. Limnol. Oceanogr. 44, 573-585 (1999). 
344 19. Hansell, D. A. \& Carlson, C. A. Biogeochemistry of total organic carbon and nitrogen in 345 the Sargasso Sea: control by convective overturn. Deep Sea Res. Part II Top. Stud. Oceanogr. 346 48, 1649-1667 (2001).

347 20. Letscher, R. T., Hansell, D. A., Carlson, C. A., Lumpkin, R. \& Knapp, A. N. Dissolved 348 organic nitrogen in the global surface ocean: Distribution and fate. Glob. Biogeochem. Cycles $349 \quad 27,141-153$ (2013).

350 21. Knapp, A. N., Casciotti, K. L. \& Prokopenko, M. G. Dissolved Organic Nitrogen Production 351 and Consumption in Eastern Tropical South Pacific Surface Waters. Glob. Biogeochem. Cycles $352 \quad 32,769-783$ (2018).

353 22. Moutin, T. et al. Nutrient availability and the ultimate control of the biological carbon 354 pump in the western tropical South Pacific Ocean. Biogeosciences 15, 2961-2989 (2018).

355 23. DeVries, T., Deutsch, C., Primeau, F., Chang, B. \& Devol, A. Global rates of water-column 356 denitrification derived from nitrogen gas measurements. Nat. Geosci. 5, 547-550 (2012).

357 24. Sohm, J. A., Mahaffey, C. \& Capone, D. G. Assessment of relative phosphorus limitation 358 of Trichodesmium spp. in the North Pacific, North Atlantic, and the north coast of Australia.

359 Limnol. Oceanogr. 53, 2495-2502 (2008).

360 25. Hashihama, F. et al. Biogeochemical Controls of Particulate Phosphorus Distribution 361 Across the Oligotrophic Subtropical Pacific Ocean. Glob. Biogeochem. Cycles 34, 362 e2020GB006669 (2020).

363 26. Mahowald, N. M. et al. Atmospheric global dust cycle and iron inputs to the ocean. Glob. 364 Biogeochem. Cycles 19, (2005). 
365 27. Guieu, C. et al. Iron from a submarine source impacts the productive layer of the

366 Western Tropical South Pacific (WTSP). Sci. Rep. 8, 9075 (2018).

367 28. Carpenter, E. J., Subramaniam, A. \& Capone, D. G. Biomass and primary productivity of 368 the cyanobacterium Trichodesmium spp. in the tropical N Atlantic ocean. Deep Sea Res. Part 369 Oceanogr. Res. Pap. 51, 173-203 (2004).

370 29. Capone, D. G. et al. Nitrogen fixation by Trichodesmium spp.: An important source of 371 new nitrogen to the tropical and subtropical North Atlantic Ocean. Glob. Biogeochem. Cycles $37219,(2005)$.

373 30. Knapp, A. N. et al. Distribution and rates of nitrogen fixation in the western tropical 374 South Pacific Ocean constrained by nitrogen isotope budgets. Biogeosciences 15, 2619-2628 375 (2018)

376 31. Caffin, M. et al. $\mathrm{N}_{2}$ fixation as a dominant new $\mathrm{N}$ source in the western tropical South 377 Pacific Ocean (OUTPACE cruise). Biogeosciences 15, 2565-2585 (2018).

378 32. Dyhrman, S. T. et al. Phosphonate utilization by the globally important marine 379 diazotroph Trichodesmium. Nature 439, 68-71 (2006).

380 33. Van Mooy, B. A. S. et al. Quorum sensing control of phosphorus acquisition in 381 Trichodesmium consortia. ISME J. 6, 422-429 (2012).

382 34. Foreman, R. K., Björkman, K. M., Carlson, C. A., Opalk, K. \& Karl, D. M. Improved 383 ultraviolet photo-oxidation system yields estimates for deep-sea dissolved organic nitrogen 384 and phosphorus. Limnol. Oceanogr. Methods 17, 277-291 (2019).

385 35. Ustick, L. J. et al. Metagenomic analysis reveals global-scale patterns of ocean nutrient 386 limitation. Science 372, 287-291 (2021). 
387 36. Weber, T. \& Deutsch, C. Local versus basin-scale limitation of marine nitrogen fixation.

388 Proc. Natl. Acad. Sci. 111, 8741-8746 (2014).

389 37. Wang, W.-L., Moore, J. K., Martiny, A. C. \& Primeau, F. W. Convergent estimates of 390 marine nitrogen fixation. Nature 566, 205-211 (2019).

391 38. Repeta, D. J. et al. Marine methane paradox explained by bacterial degradation of 392 dissolved organic matter. Nat. Geosci. 9, 884-887 (2016).

393 39. Monaghan, E. J. \& Ruttenberg, K. C. Dissolved organic phosphorus in the coastal ocean: 394 Reassessment of available methods and seasonal phosphorus profiles from the Eel River 395 Shelf. Limnol. Oceanogr. 44, 1702-1714 (1999).

396 40. Armstrong, F. a. J., Williams, P. M. \& Strickland, J. D. H. Photo-oxidation of Organic 397 Matter in Sea Water by Ultra-violet Radiation, Analytical and Other Applications. Nature 211, $398 \quad 481-483(1966)$.

399 41. Pujo-Pay, M. \& Raimbault, P. Improvement of the wet-oxidation procedure for 400 simultaneous determination of particulate organic nitrogen and phosphorus collected on 401 filters. Mar. Ecol. Prog. Ser. 105, 203-207 (1994).

402 42. Garcia, H. E. et al. World Ocean Atlas 2013. Volume 4, Dissolved inorganic nutrients 403 (phosphate, nitrate, silicate). In NOAA Atlas NESDIS 76 (eds Levitus, S. \& Mishonov, A.) 25pp. 404 (2013).

405 43. NASA Goddard Space Flight Center, Ocean Ecology Laboratory, \& Ocean Biology 406 Processing Group. Moderate-resolution Imaging Spectroradiometer (MODIS) Aqua 407 Chlorophyll a 9 km Data. NASA OB.DAAC, Greenbelt, MD, USA. 408 https://oceancolor.gsfc.nasa.gov/I3/. Accessed 20 Jan 2021. 
409 44. Westberry, T. K. et al. Annual cycles of phytoplankton biomass in the subarctic Atlantic 410 and Pacific Ocean. Glob. Biogeochem. Cycles 30, 175-190 (2016).

411 45. Trujillo-Ortiz, A. \& Hernandez-Walls, R. gmregress: Geometric Mean Regression

412 (Reduced Major Axis Regression. A MATLAB file. http://www. mathworks.

413 com/matlabcentral/fileexchange/27918-gmregress.

414 

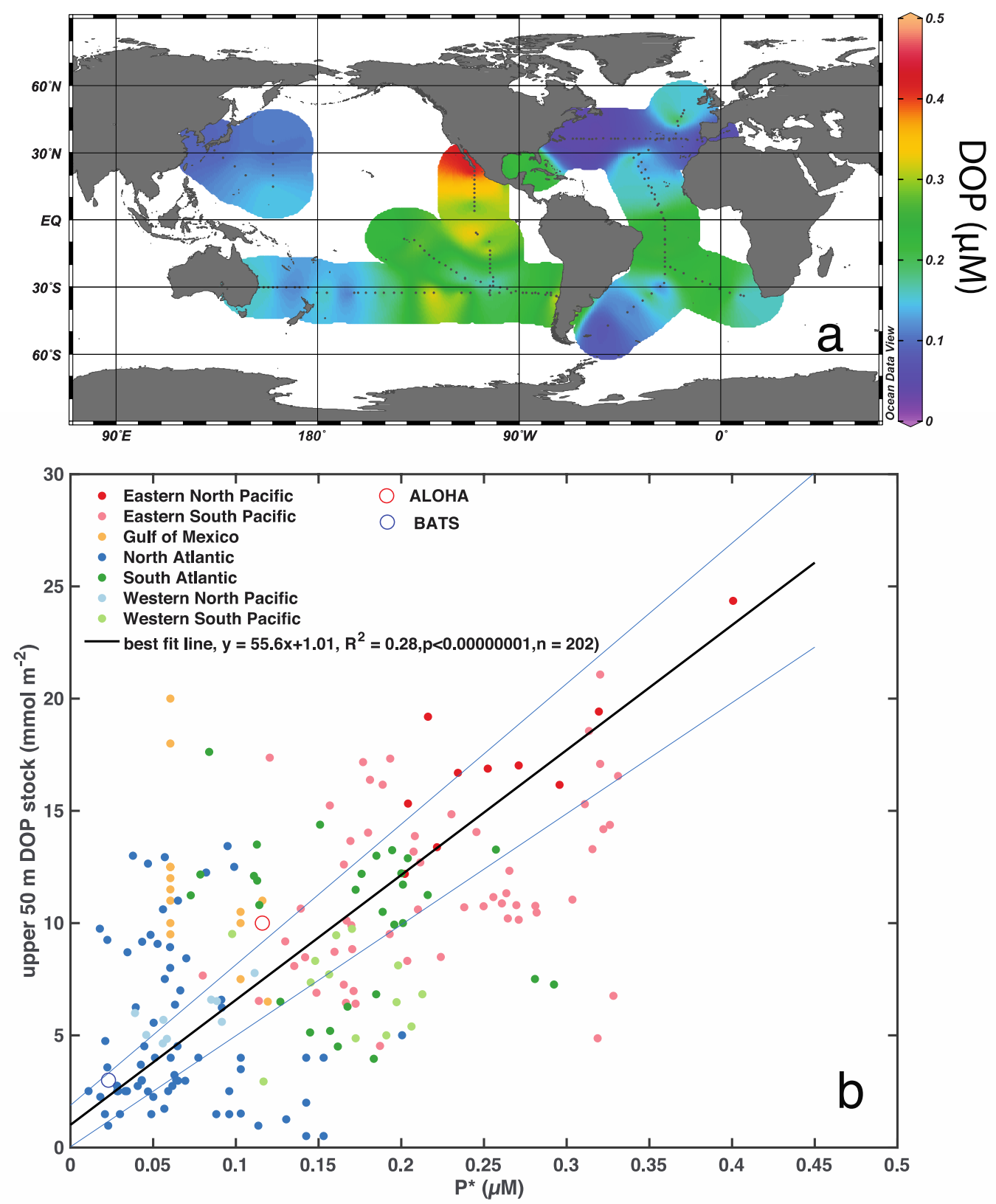

Figure 1. (a) The global distribution of mean upper $50 \mathrm{~m}$ DOP concentrations $[\mu \mathrm{M}]$. (b) Correlation between upper $50 \mathrm{~m}$ DOP stock and $\mathrm{P}^{*}(\mu \mathrm{M})$. Black solid line is the best fit line using a Type II linear regression model and blue lines are the $95 \%$ confidence level. 

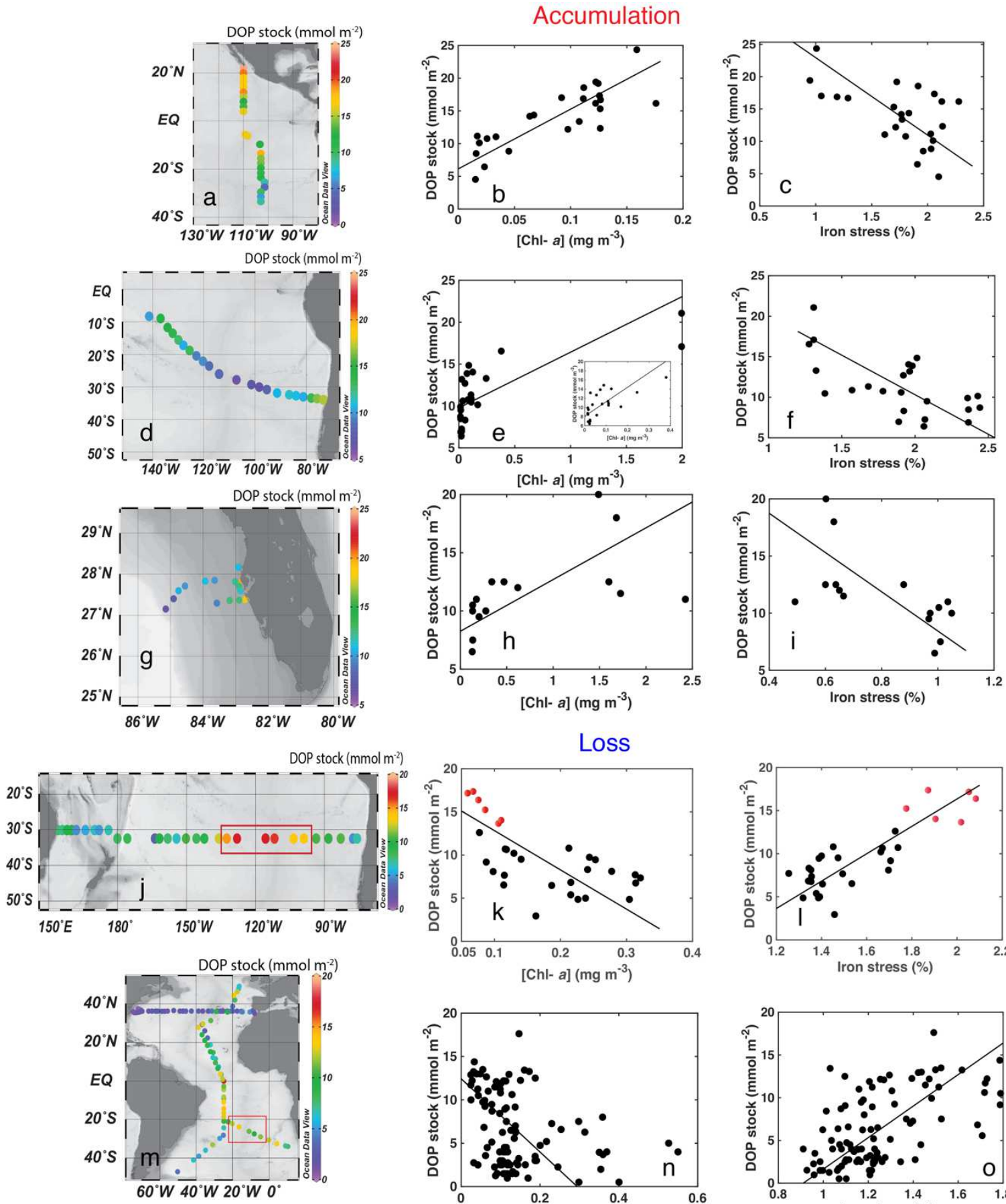

Loss
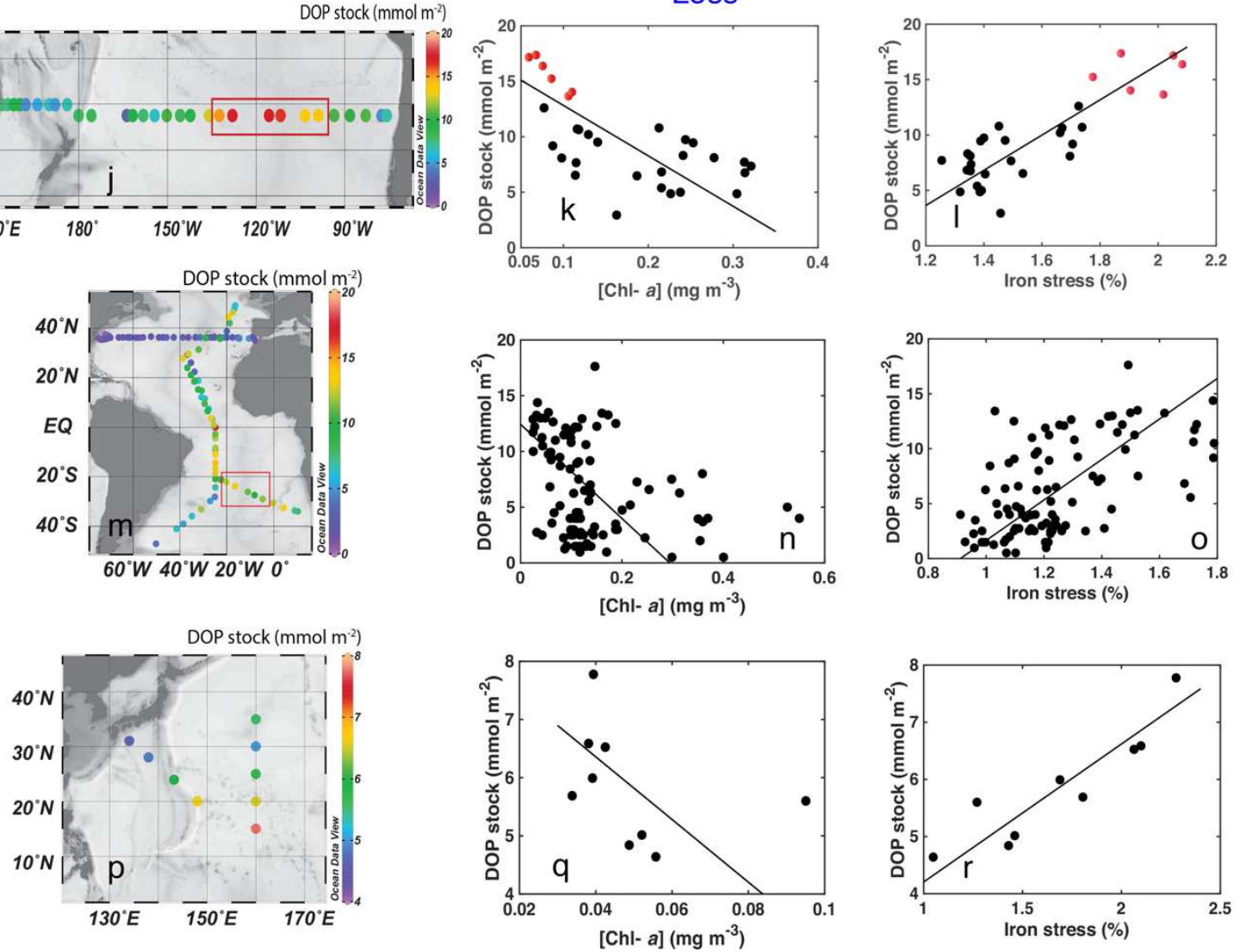
Figure 2. Relationships between upper $50 \mathrm{~m}$ DOP stock, surface chlorophyll $a$ concentration ([Chl$a]$ ), and iron stress in different basins, showing regions with DOP accumulation and loss: (a, b and c) the GO-SHIP P18-2016 in the Eastern Pacific; (d, e and f) the BIOSOPE cruise in the Eastern sub-and tropical South Pacific, one sample with $\left[\mathrm{PO}_{4}{ }^{3-}\right]>1.5 \mu \mathrm{M}$ is excluded from this analysis; ( $g$, h and i) the GOM2019 cruise in the Gulf of Mexico; (j, k and l) the GO-SHIP P06-2017 cruise in the subtropical South Pacific, where red filled circles are samples from the surface convergence zone $\left(100^{\circ} \mathrm{W}-130^{\circ} \mathrm{W}\right)$, samples from the surface convergence zone are within the red box in the map (j); (m, n and o) the AMT17, AMT 14 and 36N cruises in the Atlantic, where the surface convergence zone is circled with a red box in the map (m); (p, q and r) the KH12-3 cruise in the Western North Pacific. All black lines are lines of best fit determined with a Type II linear regression model. Note the different scales for the $x$ - and $y$-axes in the panels. Details of correlations and sample sizes from each cruise are listed in Table 1.

Table 1. Correlation analysis between upper $50 \mathrm{~m}$ DOP stock with chlorophyll $a$ and iron stress for cruises in Figure 2.

\begin{tabular}{|c|c|c|c|c|c|}
\hline Cruise & Location & Year & $\begin{array}{c}\text { DOP stock vs. chl } \\
\text { a concentration }\end{array}$ & $\begin{array}{c}\text { DOP stock vs. } \\
\text { iron stress }\end{array}$ & n \\
\hline $\begin{array}{c}\text { GO-SHIP P18- } \\
2016^{\mathrm{a}}\end{array}$ & Eastern Pacific & 2016 & $\begin{array}{c}\mathrm{R}^{2}=0.67, \\
\mathrm{p}<0.001\end{array}$ & $\begin{array}{c}\mathrm{R}^{2}=0.31, \\
\mathrm{p}<0.001\end{array}$ & 24 \\
\hline BIOSOPE $^{\mathrm{b}}$ & $\begin{array}{c}\text { Eastern South } \\
\text { Pacific }\end{array}$ & 2004 & $\begin{array}{c}\mathrm{R}^{2}=0.52, \\
\mathrm{p}<0.001\end{array}$ & $\begin{array}{c}\mathrm{R}^{2}=0.41, \\
\mathrm{p}<0.001\end{array}$ & 24 \\
\hline GOM2019 $^{\mathrm{a}}$ & Gulf of Mexico & 2019 & $\begin{array}{c}\mathrm{R}^{2}=0.30, \\
\mathrm{p}<0.001\end{array}$ & $\begin{array}{c}\mathrm{R}^{2}=0.38, \\
\mathrm{p}<0.001\end{array}$ & 15 \\
\hline AMT 17, & $\begin{array}{c}\text { North Atlantic, } \\
\text { AMT14 and } \\
36 N^{\mathrm{c}}\end{array}$ & $\begin{array}{c}\text { South Atlantic } \\
2004,\end{array}$ & $\begin{array}{c}\mathrm{R}^{2}=0.10, \\
\mathrm{p}<0.001\end{array}$ & $\begin{array}{c}\mathrm{R}^{2}=0.36, \\
\mathrm{p}<0.001\end{array}$ & 99 \\
\hline KH12-3 & $\begin{array}{c}\text { Western North } \\
\text { Pacific }\end{array}$ & 2012 & $\begin{array}{c}\mathrm{R}^{2}=0.12, \\
\mathrm{p}=0.02\end{array}$ & $\begin{array}{c}\mathrm{R}^{2}=0.82, \\
\mathrm{p}<0.001\end{array}$ & 9 \\
\hline P06-2016 & $\begin{array}{c}\text { Western and Eastern } \\
\text { South Pacific }\end{array}$ & 2016 & $\begin{array}{c}\mathrm{R}^{2}=0.41, \\
\mathrm{p}<0.001\end{array}$ & $\begin{array}{c}\mathrm{R}^{2}=0.71, \\
\mathrm{p}<0.001\end{array}$ & 30 \\
\hline
\end{tabular}

${ }^{a}$ this study

$415 \quad \mathrm{~b}$ Moutin et al., 2018

$416{ }^{\mathrm{c}}$ Mather et al., 2008

417 d Hashihama et al., 2020 


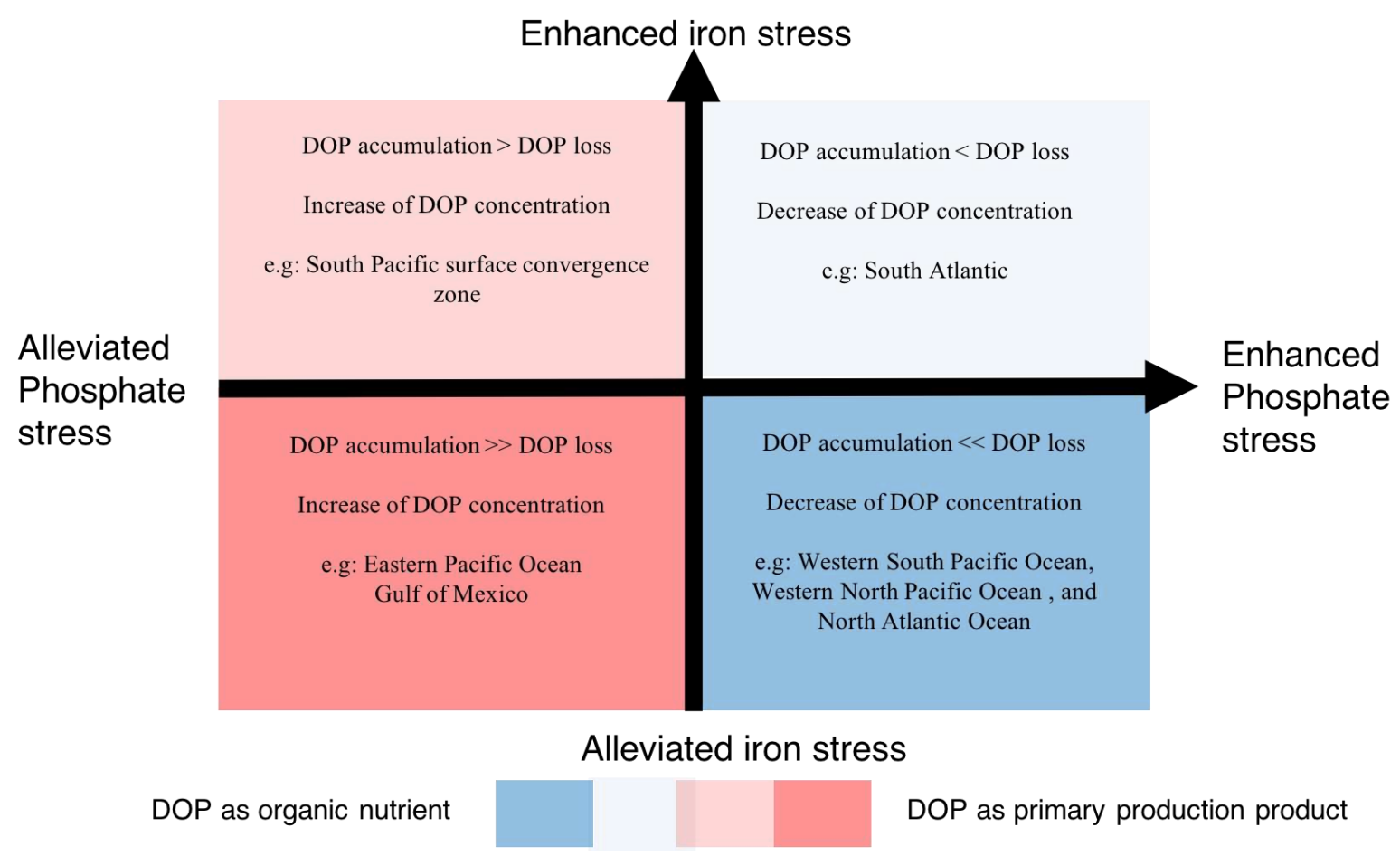

Figure 1. Conceptual model of factors influencing surface ocean DOP distributions. 


\section{Supplementary Files}

This is a list of supplementary files associated with this preprint. Click to download.

- naturegeoscienceSIfinal.docx 